\title{
UNA POSMODERNIDAD REACCIONARIA: EL PENSAMIENTO DE ÁLVARO MUTIS
}

\author{
POR \\ Gastón A. Alzate \\ California State University-Los Angeles
}

Aunque no es el propósito de este artículo discutir los múltiples sentidos que los términos "postmodernidad" y "reaccionario" pudieran tener en su uso contemporáneo, se hace necesario partir de un acuerdo inicial sobre ellos antes de aproximarnos a la obra de Álvaro Mutis. Llamaremos modernidad al proceso histórico que tiene sus orígenes en Europa a partir de la Ilustración y que propone que el individuo puede alcanzar sus metas de una manera racional a través de su voluntad, a diferencia de épocas anteriores en que estos objetivos se lograban en la relación de subordinación que el individuo establecía con la autoridad, fuera esta humana o divina. Como señala Michel Foucault en su artículo “¿Qué es la Ilustración?”, a partir de Kant el proyecto moderno es en esencia “un proceso que nos libera del estado de tutela" (199), estado que nos hace aceptar naturalmente la autoridad de otros. Esta emancipación del "estado de tutela" es la que, según Kant, está en la base de la idea de universalidad, individualidad y autonomía que subyace a la idea de una razón emancipadora (Aufklärung). Principalmente desde los siglos XVIII y XIX, varios pensadores desarrollaron conceptos en contra de este presupuesto ilustrado. "Reaccionario" sería entonces aquel que desde esa época se opone y se resiste al imperativo categórico optimista de la razón y la igualdad, señalando a la historia como el lugar por excelencia donde se manifiesta su imposibilidad. De igual forma, reaccionario es aquel que entiende el alejamiento de la humanidad de la religión y de lo sagrado como el principio de una nueva esclavitud, la de haber convertido al progreso en un dogma. A mediados del siglo XX esta fuerza dominante llamada modernidad decae por diversos motivos, entre otros, las guerras mundiales (y guerras posteriores) y el descalabro político al tratar de establecer sistemas económicos que nos liberen del azar histórico, de la injusticia y del hambre (capitalismo/comunismo). Ante la crisis de la razón y el fiasco del plan de emancipación de la humanidad de las formas tradicionales del pensamiento y el arte, la civilización da paso a una pluralidad de manifestaciones culturales escépticas al proyecto ilustrado, las cuales se manifiestan principalmente a través de la exaltación de lo híbrido y la cultura popular en las artes (lo cual es eje de la mayoría de visiones "posmodernas"); igualmente estas manifestaciones se rebelan 
ante los grandes relatos de la historia y la literatura e impugnan la autoridad científica e intelectual establecida por la tradición. Esta es la razón por la cual el pensamiento de los "postmodernos" y de los "reaccionarios" se entrecruza, porque ambos ponen en cuestión a la cultura contemporánea. Los reaccionarios, desde la Ilustración, los posmodernos, a partir de tiempos mucho más recientes. No en balde se considera a filósofos como Søren Kierkegaard y Friedrich Nietzsche (acusados igualmente de ser reaccionarios y/o de antimodernistas), como precursores del pensamiento postmoderno. Especialmente el pensamiento de Nietzsche será de gran utilidad en mi reflexión, ya que es posible establecer paralelos -si bien cada uno en su respectivo contexto históricocon la obra de Mutis. También haré referencia a ideas clave del filósofo colombiano Nicolás Gómez Dávila, con quien Mutis reconoció abiertamente su afinidad, para luego, hacia el final del artículo y de manera quizás menos predecible, conectar la visión de la posmodernidad de Jean Baudrillard con la visión reaccionaria del escritor y poeta colombiano Álvaro Mutis, eje de este ensayo.

\section{Physis, Romanticismo y Posmodernidad}

Según Fredric Jameson: "la postmodernidad es lo que queda cuando el proceso de modernización ha concluido y la naturaleza se ha ido para siempre"(10). Si bien fueron los griegos los primeros en mirar con horror esta escisión entre el hombre y lo sagrado, la posmodernidad vendría a ser el final de una larga cadena de frustradas relaciones entre el ser humano y lo que los griegos entendían por physis. Después de los helenos, esta escisión esencial, como lo desarrolla Rafael Argullol en su libro ya clásico El héroe y el único, aparece manifiestamente en el escritor romántico, quien sentía que el ser humano nunca había estado tan lejos del origen como en su época. Los paisajes de pintores como Caspar David Friedrich (1774-1840) en los que el hombre se ve minimizado por la naturaleza hasta la desaparición, o los grabados de las ruinas de antiguos monumentos romanos de Giovanni Battista Piranesi (1720-1778), expresan muy gráficamente este sentido de extrañeza en la que se hunde imperturbablemente el espíritu humano. Es indudable que la obra de Mutis plantea el desarrollo literario de una visión trágica del hombre y la naturaleza, sin embargo en este ensayo me interesa ahondar en la idea de que dicha visión, a su vez, implica una posición reaccionaria sobre la historia y la cultura.

Soy reaccionario, sí. Desde luego, lo que no soy es progresista tal y como hoy se entiende. Detesto la idea del progreso material que se ha instalado desde el racionalismo, me parece de una idiotez absoluta... El progreso debería ir mucho más allá de la invención de la penicilina o del automóvil. El único progreso que me interesa es el progreso interno, el de los sentimientos, aprender a compartir con el hombre, sabiendo que el

$111 \frac{\text { Revista Iberoamericana, Vol. LXXXIII, Núm. 258, }}{11}$ Enero-Marzo 2017, $167-188$ 
hombre es un animal peligrosísimo ... En este sentido estamos retrocediendo, cada vez más. (Fresneda, “Álvaro Mutis: entrevista”)

Con miras a dilucidar ese reaccionarismo voy a centrarme en su visión del destino humano y de las cosmovisiones imperantes en diversas etapas históricas, su cercanía con otros pensadores contemporáneos, así como el papel de la literatura y la poesía frente al desengaño de la humanidad como proyecto moderno.

\section{LA DERROTA DE LAS IDEAS}

Para el lector de la novelas y poemas de Álvaro Mutis es fácilmente observable que toda empresa iniciada por Maqroll lleva el sino de la derrota. Esto no es algo inconsciente. Maqroll sabe de la imposibilidad de llevar a buen término sus proyectos, sin embargo los emprende con tesón:

Una fervorosa vocación de felicidad constantemente traicionada, a diario desviada y desembocando siempre en la necesidad de míseros fracasos, todos por entero ajenos a lo que en lo más hondo y cierto de mi ser, he sabido siempre que debiera cumplirse si no fuera por esta querencia mía hacia una incesante derrota. (La nieve del almirante 24-25)

Como es posible ver en esta cita, no se trata de una actitud desesperada frente al fracaso, sino de una actitud en la que esta derrota se asume como un destino personal. En una entrevista con Claudia Posadas, Mutis comentaba: "No tenemos remedio, pero tampoco hay que llorar y lamentar esto. Así somos, ese es el destino de esta especie, no debemos asustarnos" ("Los paraísos secretos de Álvaro Mutis"). El naufragio mutisiano reside en ese eterno engaño del hombre sobre sí mismo al sobrevalorar sus capacidades y sus virtudes; como señala en otra entrevista: "viajando por mares, por desiertos, conquistando, destruyéndose en lo conquistado. El creer [el hombre] que deja huella de sus conocimientos, de su saber, de sus deseos y no deja absolutamente nada" (Barnechea 590). Allí mismo enfatiza que toda empresa humana es el espectáculo del hombre que cree tener el poder, el hombre que cegado por las ideas de progreso imagina una historia que se dirige a un fin que puede moldear a su antojo (576). Al margen de tal empeño, su anti-héroe Maqroll aparece rodeado de extraños personajes de ocupaciones sospechosas que bordean la ilegalidad (tráfico de armas, trata de blancas, contrabando, fabricación de explosivos, producción ilícita de alcohol o de droga), como si en esos ambientes y ocupaciones fuera más transparente el destino último del hombre.

Frente a la derrota ontológica de las empresas humanas, la obra de Mutis gira con insistencia alrededor del recuerdo de la tierra caliente, evocación que tiene por esencia no morir, y que por ello adquiere una forma de perfección precaria. En uno de sus poemas Mutis lo expresa de manera esplendorosa:

-11 11 Revista Iberoamericana, Vol. LXXXIII, Núm. 258, Enero-Marzo 2017, $167-188$ 


\begin{abstract}
Ahora, de repente, en mitad de la noche. ha regresado la lluvia sobre los cafetales y entre el vocerío vegetal de las aguas me llega la intacta materia de otros días salvada del ajeno trabajo de los años.

("Nocturno", Poesía y prosa 67)
\end{abstract}

Mutis asocia esa imposibilidad de recuperar el pasado con la idealización de la infancia, espacio que ni la escritura misma puede rescatar del todo. Sobre ello afirma:

La palabra sólo sirve como un oscuro signo borroso, de algo que quiero y necesito que permanezca: una imagen, un estado de ánimo, una emoción, una constatación de una verdad. En ese momento es esencial, necesito que permanezca. Entonces, la palabra -como un vago jeroglífico, como un torpe jeroglífico-agarra, captura, deja unos signos para que esto perdure. Así lo vivo yo. Entonces, el objeto, el paisaje, al entrar en mi poesía, entra a formar parte de todo mi mundo, de todos mis demonios, de todas mis ansiedades, de cómo veo las cosas y los seres, entra instantáneamente. (Sefami 253)

Como afirma Reina Roffé sobre la obra de Mutis, la escritura es "una puerta cancelada que simboliza el imposible regreso al utópico paraíso de la infancia". Para Mutis esta idealización toma forma en la finca de Coello en el departamento del Tolima, donde transcurrió parte de su infancia:

En cuanto al trópico, el paisaje que me interesa y que siempre está presente no es el trópico en sí, sino lo que en Colombia llamamos la tierra caliente, la tierra donde se cultiva el café, la caña de azúcar, frutas maravillosas y que está a 13 mil metros de altura, aproximadamente, en la cordillera de los Andes. Ahí fundaron mis abuelos una hacienda, Coello, en el Tolima, que después fue de mi madre. El conocimiento de esa hacienda fue el paraíso. (Posadas)

El trópico para Mutis lleva el doble signo del fracaso y del paraíso perdido, es entonces una especie de metáfora del sentido de la literatura.

No SE VIVE IMPUNEMENTE EN EL TRÓPICO

No se nace impunemente en los Balcanes

Emil Cioran

La visión mutisiana del fracaso entronca con una vertiente de la historia del pensamiento occidental conformada por aquellos pensadores que elaboraron doctrinas basadas en formas intuitivas, vitalistas y naturalistas con un carácter anti o contraracionalista, las cuales en alguna medida eran próximas al mito en la manera de

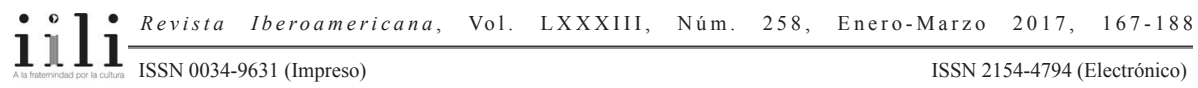


acercarse al conocimiento (González Varela 3-4). Se encuentran entre ellos figuras como Justus Möser (1720-1794), Edmund Burke (1729-1797), Joseph de Maistre (1753-1821), Arthur Schopenhauer (1788-1860), Jacob Burckhardt (1818-1897) y el ya mencionado Friedrich Nietzsche (1844-1900). En el siglo XX escritores como Louis Ferdinand Céline (1894-1961) y Emile Cioran (1911-1995) han desarrollado a su manera los diversos y complicados hilos de allí provenientes. Sin embargo, como base de las ideas reaccionarias o contra-modernas en la obra de Mutis me gustaría también añadir la influencia indirecta que ha tenido el contexto histórico colombiano.

Colombia tiene entre sus logros históricos el haber alimentado durante más de sesenta años una guerra fratricida por el control político, económico y social del país que ha generado -por lo menos en el período que va de 1981 al 2011-250.000 desaparecidos según cifras oficiales ("Informe publicado por la Fiscalía de Colombia en enero 2011”). Igualmente, en la historia reciente se han emulado crímenes que la humanidad pensó habían desaparecido de la faz de la tierra, como los hornos crematorios, los cuales fueron revividos por grupos armados ilegales de extrema derecha (paramilitares) con el objetivo de "desaparecer los desaparecidos" ("Estado Colombiano emula crímenes nazis"). Por el mismo tenor, se ha descubierto la mayor fosa común del continente americano en lo que se conoce como la sierra de La Macarena, en donde se ajusticiaron civiles inocentes falsamente identificados como bajas en combate por el ejército nacional ("Hallan fosa común con 2.000 cuerpos en La Macarena"). La guerrilla, por su parte, no se ha quedado atrás, y ha erigido campos de concentración en donde encarceló por espacio de más de quince años indiscriminadamente políticos, militares, comerciantes y campesinos. La mayoría de estos campos han sido desmantelados debido en gran parte al repudio general de la población y al nuevo proceso de paz que actualmente se lleva a cabo en La Habana, el cual se espera permitirá a la guerrilla abandonar las armas e integrarse a la vida democrática. Todo ello ha dejado huellas en la vida política, como es el hecho de que Colombia es el único país en América Latina en el que sobreviven al mismo tiempo un proyecto insurgente modelo postrevolución cubana años sesenta, al lado de una fuerte economía e industria emergentes gracias a su crecimiento constante y atractivo para la inversión extranjera, ${ }^{1}$ junto al mayor número de desplazamientos forzados del mundo ${ }^{2}$ y a una de las mayores tasas de pobreza de Latinoamérica (CIA

\footnotetext{
Colombia es la cuarta economía de América Latina después de Brasil, México y Argentina según la base de datos del World Economic Outlook del FMI (Fondo Monetario Internacional "Perspectiva de la economía mundial").

2 Según el informe anual para 2011 de la Consultoría para los Derechos Humanos y el Desplazamiento (Codhes), Colombia continúa siendo el primer país del mundo con más desplazados internos y refugiados, con una cifra de 5,2 millones de ciudadanos víctimas del desplazamiento forzado por el conflicto armado (Consultoría para los Derechos Humanos y el Desplazamiento-Codhes. Boletin 78, 2011).
}

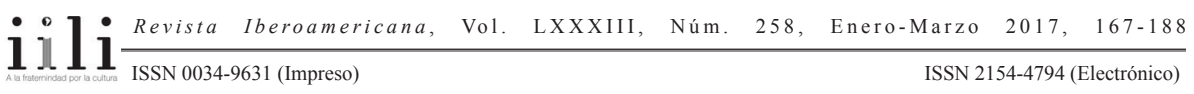


World Factbook). Este paradójico contexto económico y social se ha manifestado en el exterminio casi total de los miembros de un partido político de izquierda, la Unión Patriótica, ${ }^{3}$ y en la imposibilidad para los partidos tradicionales de ignorar a la subversión en sus planes presidenciales, ya sea para prometer fallidos diálogos de paz o para profetizar su absoluta destrucción (Chernick 29). Otra singular consecuencia es que la población en general asume todo discurso que signifique solidaridad o trabajo social como sinónimo de una condena a muerte debido a la cantidad de asesinatos de sindicalistas y líderes campesinos o comunitarios ${ }^{4} \mathrm{y}$ de periodistas que han intentado denunciar la situación ${ }^{5}$ por parte de la extrema derecha, y porque muchos discursos públicos de derecha señalan a individuos o grupos que defienden los derechos de la población como colaboradores de la guerrilla aunque no lo sean, lo cual contribuye directamente en los asesinatos y en los desplazamientos de grandes sectores de la población. Como afirma el filósofo colombiano Rubén Jaramillo Vélez, la polarización ideológica derecha contra izquierda, guerrilla contra paramilitares, progresismo frente al status quo ha producido que en Colombia la modernidad en su conjunto haya sido arrastrada por la idea de eliminar los aspectos más moderados de la cultura. Todo discurso que suene a solidaridad, todo lo que en otros contextos y países signifique participación ciudadana, es en Colombia sinónimo de extremismo. Es indudable que en parte se debe a que la guerrilla se ha apropiado del discurso progresista y democrático, y en parte debido a la estigmatización continua por parte de la derecha política y sus fuerzas represivas (paramilitares, agentes del estado) de los que se dedican al trabajo social y a la democracia directa.

En ese contexto y tratando de analizar el impacto de este ambiente polarizado en la cultura literaria, podemos decir que la mayoría de pensadores y escritores que han llegado a plantear visiones nuevas y complejas de nuestra realidad y literatura, se han decantado por una opción progresista, en ocasiones claramente de izquierda, como es el caso de García Márquez. Sin embargo, en la medida en que el conflicto se

3 El partido de la UP (1985-1990) fue fundado como parte de una propuesta política legal de varios grupos armados. Su participación llegó a obtener el tercer lugar en las elecciones presidenciales de 1986. Sin embargo, a partir de ese año comenzó lo que se ha denominado como el exterminio de esta organización por parte de grupos de narcotraficantes y paramilitares en colaboración con efectivos militares y de policía. En 1997 la Comisión Interamericana de Derechos Humanos (CIDH) aceptó el caso colectivo No. 11.227 en el que se remite una lista de 1.163 que fueron ejecutados. (El Terrorismo de Estado en Colombia) extrajudicialmente y 123 miembros de la UP que fueron desaparecidas por la fuerza entre 1985 y 1993 (Cepeda Castro).

4 En el 2011 hubo en Colombia 61 líderes comunitarios asesinados y el mayor número de sindicalistas asesinados en el mundo. En el 2012 fueron asesinados 20 sindicalistas aunque el número de amenazados fue de 90 (Noguera).

5 Según el periódico El Tiempo, a febrero de 2013 había habido 140 periodistas asesinados desde 1977, de los cuales habían prescrito 59 casos en la justicia ordinaria. Solo 17 terminaron en condena en el mismo lapso. El resto están en investigación (Redacción Justicia).

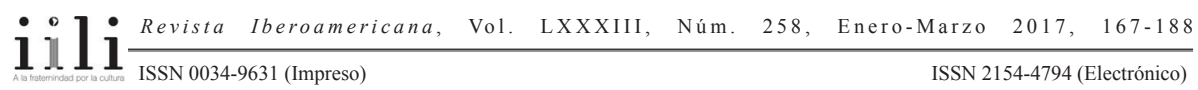


ha degradado, los intelectuales demócratas han intentando marcar la diferencia con la realidad atroz de la guerrilla, especialmente del secuestro y el narcotráfico. Por otro lado, quienes se inclinan más hacia la derecha han tendido a ejercer la palabra para apoyar abierta e insistentemente a los gobiernos conservadores de turno o a los sectores de ultra derecha como son los paramilitares. Tal es el caso del escritor Plinio Apuleyo Mendoza.

Si bien no es posible trazar una línea directa y explícita entre estos acontecimientos y la literatura escrita por Álvaro Mutis, si podemos decir que contra ese trasfondo y en contravía de posturas tanto de izquierda como de derecha se destaca significativamente su obra. En este sentido es revelador la afiliación de Álvaro Mutis al grupo MITO, conjunto de intelectuales y escritores colombianos con tendencia existencialista que crearon la famosa revista del mismo nombre. Grupo y revista se establecen en 1955 como fruto de la situación política internacional, el fin de la Segunda Guerra Mundial, y en Colombia, el sangriento enfrentamiento de los partidos tradicionales que terminó por constituir el período histórico conocido como "La Violencia" (1948-1958). Sobre este período Mutis afirmó en 1974: “A mí la violencia me dejó completamente indiferente. Es horrible, porque la violencia desangró este país, fue una lacra que lo deshizo y lo deshace. Pero los hombres y las cosas que no tengan ya la dorada lejanía de la historia, cierta grandeza, me dejan impasible, no los frecuento" ("La historia como estética" 584). Cuando se le preguntaba por las razones de su descreimiento en la política, Mutis respondía: se debe "a que lo peor de la izquierda es la derecha. La derecha es egoísta, ansiosa de dinero y de tener el poder en las manos. Y la izquierda siempre está mintiendo por el bien de los pobres" (López). Con respecto al carácter espurio de los ideales progresistas, Mutis ha dicho: "La felicidad y seamos felices y todo eso sólo pasa en los falsos paraísos socialistas" (Sheridan 109). Por lo demás, en otra entrevista publicada en la prestigiosa revista estadounidense BOMB, a la pregunta sobre sus amistades en la izquierda latinoamericana que tiende por lo general a ser muy politizada, habría de decir:

AM: Con mis amigos cercanos, los cuales son abiertamente de izquierda, nunca discuto este tema. Hablamos de literatura, de la vida y de nuestros amigos. A mí en lo particular no me interesa hablar de política.

FM: ¿Y con sus amigos de la derecha?

AM: Bueno con la gente de la derecha, con ellos tengo grandes reservas, y soy más cauto. La derecha es bastante siniestra. El poder del dinero es terrible (Goldman).

Literariamente hablando, el fracaso del libertador Simón Bolívar en el relato $E l$ último rostro (1978), puede ser interpretado como la posición ideológica mutisiana sobre la historia de Colombia desde el período así llamado como la Independencia (1819) hasta nuestros días. En este texto Mutis imagina el diario de un coronel de lanceros

\begin{tabular}{l}
-1110 Revista Iberoamericana, Vol. LXXXIII, Núm. 258, Enero-Marzo 2017, $167-188$ \\
\hline ISSN 0034-9631 (Impreso)
\end{tabular} 
polaco, Miecislaw Napierski, quien viaja desde Europa a América para alistarse en el ejército de la Gran Colombia. Napierski llega a tierras americanas cuando la causa libertadora ya ha terminado, sin embargo logra hablar con Bolívar en Santa Marta días antes de su muerte. Esto es lo que Napierski consigna en su diario sobre su conversación con Bolívar acerca de la empresa libertadora:

-Aquí se frustra toda empresa humana -comentó-. El desorden vertiginoso del paisaje, los ríos inmensos, el caos de los elementos, la vastedad de las selvas, el clima implacable, trabajan la voluntad y minan las razones profundas, esenciales, para vivir, que heredamos de ustedes. Esas razones nos impulsan todavía, pero en el camino nos perdemos en la hueca retórica y en la sanguinaria violencia que todo lo arrasa. Queda una conciencia de lo que debimos hacer y no hicimos y que sigue trabajando allá adentro, haciéndonos inconformes, astutos, frustrados, ruidosos, inconstantes. [...] ¿Sabe usted que cuando yo pedí la libertad para los esclavos, las voces clandestinas que conspiraron contra el proyecto e impidieron su cumplimiento fueron las de mis compañeros de lucha, los mismos que se jugaron la vida cruzando a mi lado los Andes para vencer en el Pantano de Vargas, en Boyacá y en Ayacucho; los mismos que habían padecido prisión y miserias sin cuento en las cárceles de Cartagena el Callao y Cádiz de manos de los españoles? [...] ¡Qué poco han valido todos los años de batallar, ordenar, sufrir, gobernar, construir, para terminar acosados por los mismos imbéciles de siempre, los astutos políticos con alma de peluquero y trucos de notario que saben matar y seguir sonriendo y adulando. Nadie ha entendido aquí nada. La muerte se llevó a los mejores, todo queda en manos de los más listos, los más sinuosos que ahora derrochan la herencia ganada con tanto dolor y tanta muerte... (El último rostro 87)

Como puede verse en el pasaje anterior, Mutis es profundamente escéptico sobre lo que comúnmente se entiende por la independencia americana. Como un hombre dedicado a un proyecto histórico de gran magnitud, el Bolívar mutisiano se da cuenta de lo ilusorio de tal empresa, pues son los "más sinuosos" y no los más lúcidos quienes siempre terminan por apropiarse de tales proyectos colectivos.

\section{LA EDAD MEDIA}

Como profundo lector de la historia europea Mutis se ha enfocado en un momento muy particular de la Edad Media para situar lo que para él es el último momento de esplendor de la historia occidental. Se trata de la caída de Bizancio en manos de los infieles el martes 29 de mayo de 1453. Mutis no indica un hecho puntual sino una serie de conflictos históricos, la mayoría bélicos, que terminaron por enfrentar a los turcos otomanos y a los griegos bizantinos, los cuales culminaron con la toma de Constantinopla y la conquista por los turcos del resto de los territorios bajo dominio bizantino (Madden 168). 
Para Álvaro Mutis, con Bizancio se pierde la última oportunidad del mundo romano de reinar en oriente. Este último esplendor de la cultura occidental ocurrirá en el amalgamiento de las cultura grecorromana y cristiana que vería la luz en la antigua ciudad de Bizancio, inicialmente llamada por el emperador Constantino I, la Nueva Roma (330 D.C.). Este proyecto, que se convertiría luego en el Imperio Romano de Oriente (Imperio Bizantino a partir del siglo XVIII), fue un Imperio multiétnico que a pesar de ser una entidad cultural diferente de Occidente, emergió como un Estado cristiano a lo largo de más de mil años y terminó como un estado Griego Ortodoxo (Treadgold 103). Constantinopla desplazó a la cultura griega y romana de su centro natural (Roma), al mismo tiempo que no rompió completamente los lazos que la unían. Fue así como desde esta ciudad "el mundo romano fue recorrido en busca de tesoros artísticos", convirtiéndola en un "verdadero museo lleno de obras maestras griegas y helenísticas" (Baynes 15).

En una época que carecía de comprensión para la tolerancia debido al fanatismo, la visión inicial de Constantino es la que más interesa a Mutis, ya que este, pese a su conversión al cristianismo, siguió leal a la política imperial que permitía a todas las sectas por igual profesar sus creencias y celebrar sus ritos religiosos.

Para Mutis, después del Imperio Bizantino "el hombre no volverá a tener ocasión de cumplir el más alto destino que recuerda su paso por la tierra" ("Intermedio en Constantinopa" 528). Esto lo podemos apreciar en el personaje Alar el Ilirio de su relato "La muerte del estratega" (1978), a quien le corresponde vivir la simbiosis y las irreversibles contradicciones entre las culturas paganas, de origen romano y griego, y la cristiana. Para Mutis esta situación no ha cambiado; por el contrario se reproduce en todas las épocas con extraordinaria prolijidad. El cristianismo, junto con otros credos del oriente, constituyó la religión de una realidad unilateral. Pese a la asombrosa fecundidad que mostró el arte bizantino, las culturas que la integraban manifestaron irreversibles distancias que produjeron a la postre el derrumbamiento del imperio. El estratega del relato de Mutis, afirma: "El Cristo nos ha sacrificado en su cruz, Buda nos ha sacrificado en su renunciación. Mahoma nos ha sacrificado en su furia" ("La muerte del estratega" 13). Para este escritor una cosa es la nostalgia por un orden cuyo fundamento desde la Grecia antigua yacía en lo sagrado, y otra el fanatismo que finalmente derrumbó a Bizancio.

\section{GNOSTICISMO Y MESIANISMO}

Pese a la importancia que Álvaro Mutis le da a Bizancio, a nivel del desarrollo del pensamiento, la semilla del fracaso es anterior a este momento histórico y tiene que ver con las ideas mesiánicas que se encuentran en las corrientes heréticas gnósticas del cristianismo del siglo I al siglo III de nuestra era. Parafraseando a Silvia Lavina en su

\begin{tabular}{l}
-1110 Revista Iberoamericana, Vol. LXXXIII, Núm. 258, Enero-Marzo 2017, $167-188$ \\
\hline ISSN 0034-9631 (Impreso)
\end{tabular} 
artículo sobre el escritor colombiano Nicolás Gómez Dávila (1913-1994), podemos decir que la historia estaba ya envenenada desde mucho antes (272). Gómez Dávila será una influencia decisiva en Mutis desde la perspectiva de la ideología reaccionaria. Vamos a detenernos brevemente en algunas reflexiones de este autor bogotano con quien Mutis compartió no sólo una ideología sino una profunda amistad.

Nicolás Gómez Dávila nunca llegó a estudiar en una universidad pese a haber sido educado en un colegio benedictino francés y de haber recibido clases impartidas por tutores en París hacia 1930. Debido a su amor por el pensamiento y las letras este filósofo colombiano pasó gran parte de su vida entre los borgianos confines de su biblioteca dedicado al estudio de la filosofía, las lenguas y las literaturas clásicas. $\mathrm{Su}$ obra consiste casi exclusivamente de textos aforísticos y notas al margen de un sistema filosófico que intencionadamente nunca construyó. Pese a haber sido admirado dentro del círculo intelectual colombiano, ${ }^{6}$ Gómez Dávila sólo alcanzó reconocimiento internacional unos años antes de su fallecimiento debido a las traducciones alemanas (Günther Rudolph Sigl) e italianas (Franco Volpi) de algunas de sus obras. ${ }^{7}$ Como origen de las ideas modernas, específicamente del progreso, Gómez Dávila señala algunas bases del cristianismo de los primeros siglos que posteriormente se desarrollaron en la Edad Media (Textos I 73). ${ }^{8}$ En Escolios I afirma Gómez Dávila: "El Renacimiento, el Aufklärung y la tecnocracia, son hijos indiscutibles del cristianismo. Hijos crecientemente siniestros que engendran en la esperanza cristiana el olvido del pecado original"(58). Para Gómez Dávila la Ilustración y sus posteriores consecuencias en las revoluciones democráticas resucitan conceptos religiosos anteriores como los de profeta, misión y

6 La relación de Gómez Dávila con políticos e intelectuales colombianos es muy conocida. Con el intelectual Mario Laserna fundó en los años cincuenta la Universidad de los Andes. Recibió oferta del presidente Alberto Lleras Camargo para ser canciller; igualmente el Directorio Conservador quiso lanzarlo como candidato a la presidencia. Gabriel García Márquez afirmó en alguna ocasión "Si no fuera de izquierda, pensaría en todo y para todo como él" (Olano García 247).

7 Franco Volpi señala en Nicolás Gómez Dávila: el solitario de Dios: "En Europa su obra empezó a ser leída gracias a las traducciones publicadas por Karolinger a partir de 1987. Un impulso importante vino del escritor Botho Strauss, cuya crítica del mundo actual deja vislumbrar claramente la lectura de los Escolios. Luego el escritor Martin Mosebach publicó en la Frankfurter Allgemeine Zeitung una sugestiva narración de sus visitas a Gómez Dávila. También Ernst Jünger, quien admiraba su obra, la define en una carta inédita, de 12 de enero de 1994: "Una mina para los amantes del conservatismo". Y el dramaturgo Heiner Müller en sus visitas a la feria del libro de Frankfurt siempre preguntaba ávidamente por nuevas traducciones de los Escolios. Con la edición publicada por Adelphi en Milán en marzo 2001 (segunda reimpresión: septiembre 2001; tercera reimpresión: marzo 2005) se ha asistido a una verdadera explosión de interés en Europa y en el mundo alimentada por la reedición de su obra original gracias a Villegas Editores. Diarios europeos líderes -como la Frankfurter Allgemeine Zeitung en Alemania y La Republica en Roma- le han dedicado a la ocasión del décimo aniversario de su muerte páginas enteras..." (81-82).

8 "La religión democrática anida en las criptas medievales, en la sombra húmeda donde bullen las larvas de textos heréticos" (Textos I 73).

$111 \frac{\text { Revista Iberoamericana, Vol. LXXXIII, Núm. 258, }}{11}$ Enero-Marzo 2017, $167-188$ 
secta. El gnosticismo pavimenta el camino al mesianismo como parámetro del hombre moderno, sea este cristiano, capitalista o comunista. Tanto para Mutis como para Gómez Dávila, las diferencias entre capitalismo y comunismo son solamente de orden jurídico, ya que ambos sistemas se basan en un criterio único al juzgar a la historia: el criterio económico. Para el pensamiento gomezdaviliano, el hombre moderno interpreta a la historia como un ente organizado y dirigido hacia la utópica llegada de un héroe/ mesías, sea este "el hombre nuevo" del socialismo o "el hombre libre" de la democracia capitalista. Afirma Gómez Dávila al respecto:

Mondado de sus excrecencias carnales, el mesianismo transmite a la Iglesia, sin embargo, el germen de sus terribles avideces. Muchedumbres esperan el descenso de la ciudad celeste y la primera encarnación del Paracleto anuncia, entre profetisas desnudas, las cosechas kiliásticas. La expectativa de un terrestre reino de los santos exalta la piedad de solitarios y la miseria de las turbas. Anhelos del alma y venganzas de la carne embriagan, con sus jugos ácidos, corazones contritos y vanidades crispadas. El mesianismo vulgar se nutre de los más nobles sueños y de las pasiones más viles. (Textos I 75)

Mutis no está muy lejos de estos pensamientos y muestra igual desaliento por las ideologías de nuestro tiempo, interpretándolas como parte de una forma de pensar facilista sobre el destino humano. Aunque Mutis no habla explícitamente del gnosticismo, es obvio que sus ideas sobre el origen de las ideas de progreso son similares y muy probablemente fueron tomadas o compartidas de las de Gómez Dávila, especialmente en lo que se refiere al mesianismo y al pensamiento utópico. Para Mutis el concepto de historia como un plan preconcebido, marcha de la civilización hacia un fin o destino manifiesto, es una ingenua quimera con la que se ha tratado de consolar a la humanidad "a fin de que no pierda toda esperanza de instalar un día el paraíso en el planeta" ("Hora de tinieblas" 209-10). Recordemos que para el escritor colombiano, "el infierno es la historia", 9 es decir los acontecimientos son "una especie de magma que se mueve y se desplaza sin propósito alguno, dando esquinazos sorprendentes, muy tristes a veces y resplandecientes otras [...]" (García Aguilar 48). Esta concepción mutisiana de la historia que podemos conjeturar como anti-gnóstica y anti-mesiánica, se refleja en los títulos de varios de sus textos: Los elementos del desastre, Los trabajos perdidos,

\footnotetext{
9 En muchas ocasiones Mutis ha utilizado esta frase de Jean Cocteau. En su ensayo "La paciencia visionaria de Miguel de Ferdinandy”, después de citarla una vez más, el escritor afirma: “... siempre me habían despertado serias sospechas los clásicos historiadores decimonónicos -Michelet y Macaulay a la cabeza- que narran la historia como una incesante lección que, escuchada y seguida por los hombres, los conduce por el camino del progreso y el cumplimiento de una vida mejor y más justa. Pero he pensado siempre como Luis Gillet que, después de Auschwitz e Hiroshima, esa clase de ingenuas necedades no es de recibo ni siquiera en personas de mediana inteligencia” (116).
}

$111 \frac{\text { Revista Iberoamericana, Vol. LXXXIII, Núm. 258, }}{11}$ Enero-Marzo 2017, $167-188$ 
Reseña de los hospitales de ultramar, títulos que evocan la idea de una "historia como muerte, desilusión y ruina" (De Roux 232).

No se me escapa que tanto para Mutis como para Gómez Dávila, existen otras épocas diferentes a la edad media consideradas como excepcionales como son las del siglo V a.C. de Grecia, el siglo de Augusto en Roma, o el Renacimiento del duca Valentino César Borgia. Sin embargo, en la Edad Media es donde se construye para ambos un pensamiento unívoco, una noción de Dios explícita que ordena, así sea momentáneamente, el natural caos de la historia; es uno de los pocos momentos excepcionales de la humanidad en los que el hombre planteó "algunas de las únicas reales posibilidades de vivir noblemente sobre la tierra"(García Aguilar 41). Mutis ha expresado su nostalgia por la pérdida de ciertos fundamentos míticos milenarios que tuvieron su última oportunidad durante esa época: "Más de una vez me he definido como un medieval perdido en este siglo" (Fresneda). En un tono afín Gómez Dávila escribió: "no soy un intelectual moderno inconforme, sino un campesino medieval indignado" (Escolios II 69).

\section{LA REFORMA PROTESTANTE Y EL RACIONALISMO}

Según Mutis, en el siglo XVI, el racionalismo desarrollará estos ideales mesiánicoutópicos a través de la noción del progreso. Lo cual es claramente observable en el pensamiento de Lutero y Calvino. A estos dos pensadores les atribuye Mutis el origen de las ideas liberales, especialmente el nacimiento de un concepto completamente extraño para la historia humana, la idea de que la vida puede ser mejorada, y aun más, puede convertirse en justa. De aquí en adelante este "credo" será asumido por la modernidad como una evidencia histórica, si bien para Mutis se trata de un quimera nunca alcanzada.

Mostrando su inquebrantable predilección por la regencia del Rey Prudente (Felipe II), Mutis asevera: "Si Felipe gana [sic] su lucha contra los herejes [protestantes] nos hubiéramos evitado males tan tremendos como la igualdad, la fraternidad, la libertad, el liberalismo manchesteriano, la libertad de cultos, la esclavitud, la libertad de las colonias y tantas otras ñoñeces de la época" (Valencia de Castaño 545).

Por su parte, Nicolás Gómez Dávila, piensa que la reforma protestante es el comienzo del fin de nuestra civilización, ya que "el dios católico se vio sustituido por la creencia en la soberanía de la voluntad humana" (Sucesivos escolios a un texto implícito 96). A partir de ese momento, los valores absolutos sobre los que se había desarrollado la idea de divinidad cayeron en desgracia, siendo substituidos por un relativismo subjetivista basado en el culto al trabajo, "el desdén de la riqueza hereditaria, de la autoridad tradicional de un nombre, de los dones gratuitos de la inteligencia o la belleza" (Textos I 80). Este racionalismo protestante produce una razón "amañada" a ciertos propósitos calvinistas y luteranos, según la visión de Mutis.

$111 \frac{\text { Revista Iberoamericana, Vol. LXXXIII, Núm. 258, }}{11}$ Enero-Marzo 2017, $167-188$ 
Con el exacerbado peso de la razón en el siglo XVIII se destruirá un entramado de ideas que le otorgaban al poder una función sagrada y un origen trascendente y que lo ponían por encima de pueriles aventuras y de varios sueños imposibles y tóxicos [se refiere a la democracia y el socialismo]. Una vez cegada esa fuente de fuerza mítica que hizo posibles los dólmenes y las catedrales, la Europa unificada que planeó desde Sicilia Federico II Hohenstaufen y el enfrentamiento de Felipe II contra el poder temporal y disociador del papado; una vez silenciada esa voz más antigua que los hermosos dibujos de Altamira, ya todo fue posible y nada puede sorprendernos. La historia se ha convertido en esa pesadilla soñada por un borracho que obsesionó con recurrente lucidez al gran Will, en “Juventud divino tesoro". (Citado por Rodolfo De Roux 236)

El creador de Maqroll desdeña las ideas de la Ilustración, especialmente la ingenuidad de los pensadores americanos que imaginaron un hombre ideal ajeno a la condición humana con el único objetivo de poder aplicar sus teorías sobre la historia del Nuevo Mundo, por tanto afirma:

el juego ya estaba hecho y ya habíamos roto con un tronco cinco veces milenario, que es el tronco hispánico, y habíamos cambiado esa inmensa tradición por algunos principios mal leídos de Juan Jacobo Rousseau, y por algunos de los principios legales y políticos nacidos de la Revolución Francesa, cuya vigencia me parece totalmente transitoria, fugaz y de una importancia mínima. ("Siempre he sido reaccionario")

La idea de progreso es pues para el pensamiento mutisiano una trampa en la que el hombre cayó irremediablemente; una trampa creada por el gnosticismo, retomada por la reforma protestante, desarrollada por la Ilustración y perpetuada por la Revolución Francesa.

\section{EL ATEÍSMO DEMOCRÁTICO Y EL ANTROPOCENTRISMO MODERNISTA}

Para el pensamiento reaccionario expresado por Álvaro Mutis, la democracia es el culmen de un derrotero histórico relacionado con el exterminio del asombro del hombre frente a lo sagrado, que ha terminado por erradicar el origen divino de su existencia. Mutis, afirma sobre la civilización romana occidental cristiana:

Si yo creo en algo y si algo me mantiene entusiasta y vivo y pegado a ciertas cosas esenciales, es la civilización romana occidental cristiana. Yo creo que esa es la realización, el cumplimiento más pleno, más grande, más ambicioso y más extraordinario del hombre sobre la tierra. Creo que estamos asistiendo a su liquidación y a su final, final que comienza con la Reforma protestante y con las ideas generadas por ella y el calvinismo, especialmente. De allí salen las ideas liberales, la tendencia racionalista, en fin, el inmenso engaño de la democracia y la hipocresía que es una de las normas

$111 \frac{\text { Revista Iberoamericana, Vol. LXXXIII, Núm. 258, }}{1} \frac{\text { Enero-Marzo 2017, }}{\text { ISSN 0034-9631 (Impreso) }}$ 
de conducta de pueblos como los Estados Unidos. Estamos en liquidación total y la negación total de una fe y del hecho de asumir un origen divino y de saberlo y vivir en ese ámbito. Eso se acabó. Como lo he dicho muchas veces, estamos viviendo en un mundo de Gulag y de supermercado (García Aguilar 36).

Como lector cuidadoso de la historia, Mutis encuentra que los presupuestos de la modernidad no pertenecen a una fe auténtica y por tanto son cínicamente falsos. Ante el cúmulo de distorsiones históricas en los que se ha convertido la democracia, Mutis se decanta por el sistema monárquico como un sistema plausible, aunque irrecuperable. Para el colombiano no hay mucho de donde escoger, mientras la democracia proclama la soberanía del hombre, la monarquía conferida por la divinidad proclamaba la soberanía de lo sacro:

\begin{abstract}
A mí me parece una falta de respeto tratar de explicarle a alguien que la democracia es una farsa. Es una mentira y es un sueño imbécil. La mayoría no puede producir sino necedades y soluciones mediocres, intermedias y falsas [...] Me parece mucho más honesto un monarca de la Edad Media que dice: 'Yo mando porque estoy ungido por el Señor. He sido ungido en la catedral de Reims. Desnudo el pecho me han puesto los óleos y tengo un compromiso ante Dios'. Ese juego lo juego yo. Pero que me digan que ese señor puede gobernar porque tiene 40 millones de votos es justamente la razón por la cual yo nunca lo dejaría gobernar un minuto, porque a 40 millones de personas no puede ocurrírseles sino una imbecilidad. (García Aguilar 44)
\end{abstract}

Como antecedente de esa desconfianza hacia la modernidad, está uno de los más importantes pensadores antimodernistas, Friedrich Nietzsche, para quien la modernidad es un "antropoteísmo" porque sitúa al ser humano como medida de todas las cosas. Para el filósofo alemán, mientras el mundo grecorromano asume la desigualdad como principio general, el pensamiento judeocristiano impondrá una civilización en la que todos los hombres son iguales ante Dios. Guardadas las debidas proporciones, tiempos históricos y contextos culturales, Nietzsche y Mutis comparten la idea de un aristocratismo como forma vital del pensador, que se va paralelo a la idea de la existencia/ la historia como un fenómeno estético ${ }^{10}$ solo que en Nietzsche este aristocratismo se dirige a la vida, y en Mutis, se dirige a la nostalgia por un orden sagrado y perdido en

${ }_{10}$ En El origen de la tragedia Nietzsche afirma: "Solo como fenómeno estético se justifica la existencia y el mundo por toda la eternidad" (47). Mutis afirma sobre su interés en la época napoleónica "[me interesa] el fenómeno teatral. Estos jóvenes franceses lanzándose a los campos de Italia, ganando batallas maravillosas dirigidos por un general de 26 años que todavía se rascaba la sarna que había contraído en Tolón. Ese joven imponiendo tratados a un imperio que tenía 700 años como el de los Habsburgos, me parece que tiene una inmensa belleza." ("La historia como estética" 586)

$111 \frac{\text { Revista Iberoamericana, Vol. LXXXIII, Núm. 258, Enero-Marzo 2017, }}{1167-188}$ 
el medioevo feudal. ${ }^{11}$ Nietzsche pensaba que "el antropocentrismo de la Modernidad, era una herencia hebrea que había desembocado en la Revolución Francesa, colocando en el centro del cosmos a los seres más mediocres, débiles e inferiores" (González Varela 21). Dice Nietzsche en Escritos de juventud: "Es un pensamiento terrible saber que un sinnúmero de cabezas mediocres se ocupan de cosas realmente influyentes" (320). Igualmente en Álvaro Mutis, aunque por medio de una expresión literaria, encontramos semejanzas con estas ideas cuando se refiere a los seres anodinos que han tomado la historia. Precisamente a estos hombres vulgares que han terminado por gobernarnos, es a los que Mutis dedica su poema "Balada imprecatoria contra los listos". Este fragmento se explica por sí solo:

Ahí pasan los listos.

Siempre de prisa, alertas, husmeando

la más leve oportunidad de poner a prueba

sus talentos, sus mañas,

su destreza al parecer sin límites.

Vienen, van, se reúnen, discuten, parten.

Sonrientes regresan con renovadas fuerzas.

Piensan que han logrado convencer, tornan a sonreír, nos ponen las manos sobre los hombros, nos protegen, nos halagan, despliegan diligentes su abanico de promesas y de nuevo se esfuman como vinieron, con su aura de inocencia satisfecha que los denuncia a leguas.

(Summa de Maqroll el Gaviero 288-89)

Ese tiempo del hombre liberal que puja hacia adelante en un movimiento imaginario de cambio, de vértigo futurista, es desenmascarado tanto en la obra de Nietzsche como en la de Mutis. Para el escritor colombiano el progreso material es una forma de encubrir el retroceso real de la cultura. Según Mutis, "El hombre vendió su espíritu por la electrónica y una serie de trucos de magia de la modernidad" (López).

\section{UN POSTMODERNO REACCIONARIO}

Como hemos visto, Álvaro Mutis tiene una concepción escéptica de la historia en contravía al proyecto de la Razón. Tal juicio tiene secuelas en su literatura. Mutis concibe la escritura a modo de signos de lo irrecuperable. A esta escritura se le ve girar

1 Hago libre uso aquí de algunas ideas de Carlos B. Gutierrez en su artículo "La crítica a la democracia en Nietzsche y Gómez Dávila” que yo extiendo al pensamiento de Álvaro Mutis. 
en su obra poética y narrativa alrededor de una estética de "tierra caliente" centrada en el deterioro y encarnada en un personaje de dudosa reputación y oficio, Maqroll el gaviero, quien habita sin esperanza puertos y territorios remotos. Su concepción de la fe también se ve afectada por este escepticismo y se manifiesta como sumisión a una única fuente posible de orden, de poder y de autoridad; la monárquica. Mutis tiene además, como buen posmoderno, una aversión a las grandes narrativas, una escritura muy personal no comprometida con causas inmediatas o políticas sino exclusivamente con él mismo, una crítica tanto a la ideología burguesa-democrática como a la proletariaprogresista, a las que ve como el punto final de la civilización occidental. Asimismo, Mutis desarrolló a lo largo de su vida ciertas obsesiones histórico-filosóficas tan recurrentes que a menudo la crítica considera su obras como un retorno asfixiante a los mismos temas (el mito perdido, la historia como un azar ininteligible, el deterioro de las civilizaciones, Bizancio, Felipe II, entre otros). Para Mutis, el desarrollo de las ideas de progreso ha terminado por excluir de nuestra existencia concepciones tan esenciales para el ser humano como son el error, la desventura y el dolor. Es por ello que en su obra, la cultura estadounidense, fundamentalmente demócrata y liberal, es el objeto de gran parte de sus críticas. Hablando de su alter ego en relación con esta cultura, Mutis afirma:

Maqroll no es feliz nunca y esa meta y especie de sueño llamada felicidad es una cosa bastante americana y protestante, es una necedad inmensa. No se viene al mundo únicamente a ser feliz, se viene a vivir, a ser desventurado, a ser feliz, a ser fracasado, y a realizar algo que soñamos. Es un ir y venir, y él lo tiene muy claro. Él no busca la felicidad en ninguna de sus empresas, lo que busca es vivir el presente, llenar el presente de sentido. (Moreno Zerpa)

La cultura de la felicidad y la libertad en la democracia política y social es para el autor colombiano una traba en la configuración moral del hombre desde la Revolución Francesa. Es Nietzsche, precisamente, uno de los primeros que en Occidente criticará la visión moral revolucionaria como una certeza nacida del resentimiento. En La genealogía de la moral dice el filosofo alemán:

La rebelión de los esclavos en la moral comienza por el hecho de que el resentimiento mismo se hace creador y engendra valores, el resentimiento de aquellos seres a los que les está negada la auténtica reacción, la de la acción, y que solo se mantienen indemnes mediante una venganza imaginaria. (170)

Esta moral revolucionaria o Sklavenmoral (moral de esclavos) según Nietzsche, se convertirá, con el paso del tiempo, en un verdadero deus ex machina de la modernidad secularizada, a la que el filósofo alemán opondrá su tesis del "eterno retorno de lo idéntico"

$111 \frac{\text { Revista Iberoamericana, Vol. LXXXIII, Núm. 258, Enero-Marzo 2017, } 167-188}{\text { ISSN 0034-9631 (Impreso) }}$ 
(Así habló Zaratustra), que es su forma de contradecir la visión unilinear del tiempo progresista. Para Nietzsche, la sociedad griega es lo suficientemente "honrada" para no encubrir el fondo "inhumano" del que provenía su riqueza y cultura: la esclavitud. Por el contrario, en la ilusión democrática esta condición desigual y trágica de la existencia es silenciada por la ideología liberal que proclama una igualdad a ultranza. Nietzsche dirá en El origen de la tragedia: "No se puede ser moral mientras el curso de las cosas humanas está determinado por la violencia, el engaño y la injusticia" (152). Como afirma Rüdiger Safranski, el filosofo alemán "no rechaza la moral, pero critica la presunción de la justicia propia y el singular optimismo de mejorar el mundo, que normalmente va unido al moralismo" (109).

Es indudable que estas posturas se hallan en concordancia con las más feroces críticas de la sociedad de consumo en la posmodernidad, entendida ésta como la creadora de un simulacro de realidad. Como afirma Jean Baudrillard, la primacía de los símbolos sobre las cosas, característica de la sociedad de masas, es un fenómeno cada vez más extendido. Por ello, en nuestros días, la representación de la realidad se sobrepone a la realidad misma formando una especie de hiperrealidad (Cultura y Simulacro 11).

Esta condición postmoderna es para el pensamiento reaccionario, una prueba más del fin de nuestra civilización. Por ejemplo, para Álvaro Mutis la cultura contemporánea, tan proclive a seguir las dinámicas del mercado estadounidense, terminará convirtiendo al ser humano en una serie de espejismos vacuos cada vez más alejados de la vida, hasta llegar a su fin: "la persona, el individuo, se está diluyendo ya en una serie de fantasmas que aparecen en pantallas y de presencias que no son presencias, y el hombre está entrando en una rutina, al tiempo que vive una vida de supermercado" (Echart y Martínez 22). Mutis piensa incluso que a este hombre, solo le sobrevivirá la poesía "Será lo último que el hombre hará. Su adiós, su glosa sobre la tierra" (López).

Así el pensamiento reaccionario mutisiano parece acercarse a las críticas más comunes al capitalismo global, multinacional o transnacional, a la sociedad postindustrial y de consumo, o a la alta tecnología provengan estas de pensadores neolacanianohegelianos como Žižek, neomarxistas-kantianos como Habermas o postestructuralistas como Derrida. Pero a diferencia de dichas críticas, el autor colombiano no considera que tenga sentido alguno engañarse tratando de plantear una sociedad más justa por medio de propuestas filosóficas o políticas. De modo radicalmente distinto, su crítica a la sociedad de consumo y a los límites de la racionalidad moderna se entreteje constantemente con una percepción anacrónica, de raigambre romántica, en la que la naturaleza desordenada es entendida como primigenia y libre. ${ }^{12}$. Esta concepción romántica también abarca el sentido de la historia en este escritor, ya que no conduce

12 Francia Elena Goenaga Olivares usa esta idea en su artículo sobre Nicolás Gómez Dávila, "La tumba habitada" (17-28). La reconsidero aquí porque creo que es extensible a Álvaro Mutis.

$111 \frac{\text { Revista Iberoamericana, Vol. LXXXIII, Núm. 258, Enero-Marzo 2017, }}{1167-188}$ 
a ninguna parte ni es concebida como una cadena organizada de acontecimientos, sino como un caos.

Podríamos concluir este ensayo diciendo que la obra de Álvaro Mutis lleva en sí una protesta contra una época desprovista de ideales heroicos. Aunque sabe que su empresa es estéril, construye un nuevo tipo de heroicidad que en nuestra época sólo le es posible al pensador o al artista. Mutis coincide con la visión de escritores románticos -en particular el poeta suabo Friederich Hölderlin-para quien la modernidad comenzaba en el Edipo de Sófocles, ya que en esta tragedia, por primera vez, la naturaleza permanece inmutable y el héroe se representa invadido por un profundo temor ante el inexplicable silencio de lo sagrado (ver Vernant y Vidal-Nanquet). En estas circunstancias trágicas el héroe, solo frente a su efímero destino, se ve forzado al sacrificio o a la inmolación (si quiere de alguna forma arrebatar algún sentido a la existencia). Sin embargo, el hombre trágico encuentra otra alternativa: puede optar por una muerte silenciosa, que es lo que finalmente realiza Edipo, y que es a nuestro parecer lo que desarrolla el escritor colombiano a través su personaje y alter ego Maqroll el Gaviero. Maqroll será entendido entonces como una metáfora del hombre contemporáneo y por ende posmoderno, ya que descree del ser humano como proyecto histórico y consume sus días divagando sin reposo a través de poblaciones perdidas en las estribaciones de la cordillera, en trenes que recorren sin término estaciones remotas, en habitaciones de hoteles sin nombre, en las altas y perdidas cascadas, en las grandes salas de los hospitales de ultramar y especialmente en barcos al borde del desahucio como es el caso del Tramp Steamer en su obra Las nieves del almirante (1986). Puede decirse que en su antimodernidad, la obra de Mutis se encuentra situada en ese preciso instante que Fredric Jameson identifica con la postmodernidad, en el que no hay vuelta atrás, momento que Mutis concibe como enraizado en la historia occidental medieval con sus imperios, su Iglesia y sobre todo, sus derrotas.

Al comparar las ideas reaccionarias de Álvaro Mutis con el filósofo más importante de la anti-modernidad, Friedricho Nietzsche, podemos decir que mientras el alemán en su radicalismo aristocrático y anti-ilustrado propondrá al Übermensch (suprahombre) como la vía para aferrarse al "sentido" de la vida en su orden jerárquico natural, con Mutis nos encontramos en la orilla opuesta. En los apuntes para La voluntad de poder dice Nietzsche: "Las cualidades específicas de la vida -la injusticia, la mentira, el saqueo- se dan con mayor grado en los grandes hombres" (202). En un pasaje de El ocaso de los ídolos: "El hombre que se ha liberado, y ¡cuanto más el espíritu que se ha liberado!, pisotea la despreciable manera de bienestar con la que sueñan tenderos, cristianos, vacas, mujeres, ingleses y otros demócratas. El hombre libre es guerrero" (139). Es evidente que para Nietzsche el Übermensch es fundamentalmente un hombre de acción, un hombre capaz de vencer el pensamiento judeo-cristiano-socrático que se ha apoderado de la historia, un hombre fundamentalmente dionisíaco, con todo lo que

$111 \frac{\text { Revista Iberoamericana, Vol. LXXXIII, Núm. 258, Enero-Marzo 2017, }}{1167-188}$ 
implica ese término en Nietzsche de abismo, "un abismo que constituye una amenaza para nuestros intentos apolíneos" (Safranski 368).

Contrariamente al alemán, para los reaccionarios colombianos Gómez Dávila y Mutis, en nuestros días, la acción ha perdido todo sentido. Gómez Dávila lo señala así: "El reaccionario no se abstiene de actuar porque el riesgo lo espante, sino porque estima que actualmente las fuerzas sociales se vierten raudas hacia la meta que desdeña". ("El reaccionario auténtico" 17) Mutis lo dice más poéticamente en "Batallas hubo":

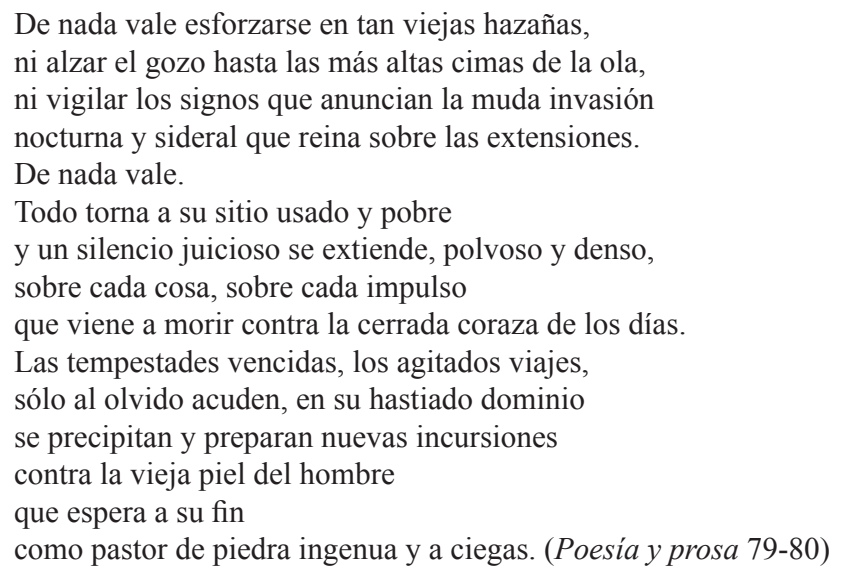

Este poema nos sustrae al corazón mismo del pensamiento mutisiano, el escritor reaccionario es un desertado de los dioses, un atheos en el sentido griego de la palabra (Alzate 119), quien ante la posibilidad de ser diluido por la divinidad (como en el caso de Empédocles) o consumido por la locura (como en el caso de Hölderlin o del mismo Nietzsche), opta por la soledad de un largo deambular como en el Edipo de Sófocles.

\section{BiBLIOGRAFÍA}

Alzate, Gastón. Sófocles, Hölderlin y Mutis. Bogotá: Colcultura, 1992.

Argullol, Rafael. El héroe y el Único: el espíritu trágico del Romanticismo. Barcelona: Taurus, 1984.

Barnechea, Alfredo y José Miguel Oviedo. "La historia como estética. Entrevista con Álvaro Mutis". Poesía y Prosa. Bogotá: Instituto Colombiano de Cultura, 1981. Baudrillard, Jean. Cultura y Simulacro. Barcelona: Editorial Kairos, 2007. Baynes, Norman H. El Imperio bizantino. México D.F.: Fondo de Cultura Económica, 1996. 
Cepeda Castro, Iván. "Genocidio político: el caso de la unión patriótica en Colombia". Proyecto desaparecidos. 2006. <http://www.desaparecidos.org/colombia/ fmcepeda/genocidio-up/cepeda.html>. 25 abril 2016.

Chernick, Marck. "Negociated settlement to armed conflict: lessons from the Colombian peace process". Journrevistagggal of Interamerican Studies and World Affairs 30/4 (1989): 27-45.

CIA World Factbook 2012. <https://www.cia.gov/library/publications/the-worldfactbook/fields/2046.html $>$.

Consultoría para los Derechos Humanos y el Desplazamiento (Codhes). Boletin 78 (2011). <http://reliefweb.int/organization/codhes>.

Echart, Nazareth y Julio Martínez Mesanza. "Entrevista a Álvaro Mutis". Nueva Revista 060 (1998): 22. <http://www.fundacionunir.net/items/show/1275>.

El Terrorismo de Estado en Colombia. Editado por varias organizaciones internacionales de derechos humanos. Ediciones NCOS. Bruselas, 1992.

"Estado Colombiano emula crímenes Nazis: Paramilitares y Hornos Crematorios". Kaosenlared.net. $<$ http://www.kaosenlared.net/noticia/estado-colombiano-emulacrimenes-nazis-paramilitares-hornos-crematorio $>$.

Foucault, Michel. “¿Qué es la Ilustración?”. Saber y Verdad. Madrid: Las Ediciones de la Piqueta, 1991. 197-207.

Fresneda, Carlos. “Álvaro Mutis: entrevista”. El Mundo: La revista 90. 6 julio 1997.

Goenaga Olivares, Francia Elena. "La tumba habitada". Paradoxa 7/14 (2007): 17-28.

García Aguilar, Eduardo. Celebraciones y otros fantasmas. Una biografía intelectual de Álvaro Mutis. Bogotá: Tercer Mundo Editores. 1993.

Goldman, Francisco. "Alvaro Mutis (entrevista)". Marina Harss, trad. BOMB: LITERATURE 74 (2001).

Gómez Dávila, Nicolás. "El reaccionario auténtico". Revista Universidad de Antioquia 240 (1995): 17-21.

Escolios I. Bogotá: Procultura, 1986.

Escolios II. Bogotá: Procultura, 1986.

Sucesivos escolios a un texto implícito. Bogotá: Villegas Editores, 2005.

Textos I. Bogotá: Villegas Editores, 2002.

González Varela, Nicolás. Nietzsche contra la democracia. Barcelona: Montesinos, 2010.

Gutiérrez, Carlos Bernardo. "La crítica a la democracia en Nietzsche y Gómez Dávila". Ideas y valores 136 (2008): 117-131.

"Hallan fosa común con 2.000 cuerpos en La Macarena". El espectador (11 dic. 2009). <http://www.elespectador.com/noticias/judicial/articulo176848-hallanfosa-comun-2000-cuerpos-macarena>.

"Informe publicado por la Fiscalía de Colombia en enero 2011". $<$ http://www.fiscalia. gov.co/justiciapaz/Index.htm>.

$111 \frac{\text { Revista Iberoamericana, Vol. LXXXIII, Núm. 258, Enero-Marzo 2017, }}{1167-188}$ 
Jameson, Fredric. Teoría de la postmodernidad. Madrid: Trotta, 1996.

Jaramillo Vélez, Rubén. Colombia: la modernidad postergada. Bogotá: Argumentos, 1998.

Lavina, Silvia. "La idiosincrasia antimoderna de Nicolás Gómez Dávila". Eikasia revista de filosofía (2012): 272.

López, Ángeles. "El Rey me dice 'Mutis: no tienes remedio"”. Literaturas.com 10. $<\mathrm{http}$ ://www.literaturas.com/v010/sec1001/entrevistas/entrevistas-01.html $>$.

Madden, Thomas F. Crusades the Illustrated History. Ann Arbor: U of Michigan P, 2005.

Moreno Zerpa, Juan Jesús. “Maqroll El Gaviero, un peregrino elegido por los Dioses: entrevista con Alvaro Mutis". Espejo de paciencia 3 (1997): 11-16.

Mutis, Álvaro. "La historia como estética: Entrevista con Alfredo Barnechea y José Miguel Oviedo”. Poesía y Prosa. Bogotá: Instituto Colombiano de Cultura, 1981. 576-597.

“Hora de tinieblas". De lecturas y algo del mundo (1943-1998). Bogotá: Seix Barral, 1999.

“Intermedio en Constantinopla”. Poesía y Prosa. Bogotá: Instituto Colombiano de Cultura, 1981. 528.

"La muerte del estratega". Los rostros del estratega. México: Fondo de Cultura Económica, 1997. 13.

La nieve del almirante. Madrid: Alianza Tres, 1987.

"Nocturno". Poesía y Prosa. Bogotá: Instituto Colombiano de Cultura, 1981. 67. "La paciencia visionaria de Miguel de Ferdinandy". De lecturas y algo del mundo (1943-1998). Bogotá: Seix Barral, 1999.

Poesía y Prosa. Bogotá: Instituto Colombiano de Cultura, 1981.

"Siempre he sido reaccionario". Semana. 6 junio 1988. <http://www.semana. com/cultura/siempre-he-sido-reaccionario/24722-3.aspx $>$.

Summa de Maqroll el Gaviero: Poesía Reunida. México: Fondo de Cultura Económica, 2002.

El último rostro. Madrid: Ciruela, 1990. 87.

Nietzsche, Friedrich. Así habló Zaratustra. Madrid: Valdemar, 2005.

La genealogía de la moral. Madrid: Alianza, 1997.

Obras completas. Volumen I. Escritos de Juventud. Joan B. Llihares, et al., trad.

Madrid: Editorial Tecnos, 2011.

El ocaso de los ídolos. Barcelona: Tusquets, 1998.

El origen de la tragedia. Buenos Aires: Terramar Ediciones, 2008.

La voluntad de poder. Madrid: EDAF, 2000.

Noguera Domínguez, Gustavo. "Líderes desplazados asesinados por reclamar tierra y exigir los derechos de población desplazada". Semanario Virtual Caja de Herramientas Edición $\mathrm{N}^{\circ}$ 00251. <http://www.viva.org.co/cajavirtual/svc0251/ articulo05.html>.

$111 \frac{\text { Revista Iberoamericana, Vol. LXXXIII, Núm. 258, }}{11} \frac{\text { Enero-Marzo 2017, }}{167-188}$ 
Olano García, Hernán Alejandro. “Aproximación al pensamiento de Nicolás Gómez Dávila sobre los derechos fundamentales. Revisión de su obra de iure". Revista de Derecho, universidad del Norte 34 (2010): 239-82.

"Perspectiva de la economía mundial". World Economic Outlook del FMI (Fondo Monetario Internacional) 17 de abril de 2012.

Posadas, Claudia. "Los paraísos secretos de Álvaro Mutis". Espéculo: Revista de estudios literarios 27 (2004). <http://www.ucm.es/info/especulo/numero27/amutis.html>. Redacción Justicia. "Han prescrito 59 casos de periodistas". El tiempo. 8 feb. 2013.

Roffé, Reina. "El trance de la escritura autobiográfica: Diario de Lecumberri”. Centro virtual Cervantes. <http://cvc.cervantes.es/actcult/mutis/acerca/roffe.htm>.

Roux, Rodolfo de. “Alvaro Mutis: La historia sin ilusiones”. Cahiers du monde hispanique et luso-brésilien 86 (2006).

Sefamí, Jacobo. "Entrevista con Jacobo Sefamí". Tras las rutas de Maqroll el Gaviero, 1988-1993. Santiago Mutis Durán, ed. Bogotá: Instituto Colombiano de Cultura, 1993.

Sheridan, Guillermo. "Los emisarios de Álvaro Mutis". Tras las rutas de Maqroll el Gaviero. Cali: Proartes, 1988. 109.

Safranski, Rüdiger. Nietzsche: autobiografía de su pensamiento. Barcelona: Tusquets, 2000.

Treadgold, Warren. A History of the Byzantine State and Society. Stanford: Stanford UP, 1997.

Valencia de Castaño, Gloria, “¿En qué época le hubiera gustado vivir?” Poesía y prosa. Santiago Mutis Durán, ed. Bogotá: Instituto Colombiano de Cultura, 1982. 545.

Vernant, Jean-Pierre y Pierre Vidal-Nanquet. Mito y tragedia en la antigua grecia V. 1. Barcelona: Paidós, 2002.

Volpi, Franco. Nicolás Gómez Dávila: el solitario de Dios. Bogotá: Villegas Editores, 2005.

$111 \frac{\text { Revista Iberoamericana, Vol. LXXXIII, Núm. 258, Enero-Marzo 2017, } 167-188}{\text { ISSN 0034-9631 (Impreso) }}$ 